07

\title{
Мощные СВЧ-фотодиоды на основе гетероструктур InAIAs/InGaAs, синтезируемых методом молекулярно-лучевой эпитаксии
}

\author{
() К.С. Журавлев, ${ }^{1,2}$ А.М. Гилинский, ${ }^{1}$ И.Б. Чистохин, ${ }^{1}$ Н.А. Валишева, ${ }^{1}$ Д.В. Дмитриев, ${ }^{1}$ \\ А.И. Торопов, ${ }^{1}$ М.С. Аксенов, ${ }^{1,2}$ А.Л. Чиж, ${ }^{3}$ К.Б. Микитчук ${ }^{3}$ \\ ${ }^{1}$ Институт фоизики полупроводников им. А.В. Ржанова СО РАН, \\ 630090 Новосибирск, Россия \\ ${ }^{2}$ Новосибирский государственный университет, \\ 630090 Новосибирск, Россия \\ ${ }^{3}$ Государственное научно-производственное объединение „Оптика, оптоэлектроника и лазерная техника“ НАН Беларуси, \\ 220090 Минск, Беларусь \\ e-mail: zhur@isp.nsc.ru
}

Поступило в Редакцию 16 декабря 2020 г.

В окончательной редакции 24 февраля 2021 г.

Принято к публикации 1 марта 2021 г.

Описаны конструкция и технологии изготовления мощных СВЧ-мезафотодиодов с барьером Шоттки диаметром от 10 до $40 \mu \mathrm{m}$ и обратной засветкой через подложку на основе гетероструктур InAlAs/InGaAs/InP, выращиваемых методом молекулярно-лучевой эпитаксии. Рабочая частота фотодиодов диаметром $10 \mu \mathrm{m}$ составляет $40 \mathrm{GHz}$, а максимальная выходная СВЧ-мощность на частоте $20 \mathrm{GHz}$ для фотодиодов диаметром $15 \mu \mathrm{m}$ достигает $58 \mathrm{~mW}$. Коэффициент амплитудно-фазового преобразования составил $1.5 \mathrm{rad} / \mathrm{W}$, что превосходит литературные данные и делает данную конструкцию фотодиодов перспективной для применения в системах генерации и передачи аналоговых СВЧ-сигналов с высокими требованиями к фазовым шумам.

Ключевые слова: мощные СВЧ-фотодиоды, гетероструктуры InAlAs/InGaAs, барьер Шоттки, планарная технология.

DOI: 10.21883/JTF.2021.07.50957.347-20

\section{Введение}

Постоянное расширение рабочих частотных диапазонов аналоговых систем связи, радиолокации и передачи информации привело к возникновению ограничений на дальность передачи СВЧ-сигналов по традиционным коаксиальным линиям из-за значительного роста величины потерь мощности сигнала с ростом его частоты. Так, при повышении частоты сигнала до 70-100 GHz величина потерь в коаксиальной линии передачи растет до $8-10 \mathrm{~dB} / \mathrm{m}$, что затрудняет передачу сигнала на расстояние свыше нескольких метров. Решение проблемы ограничения дальности передачи состоит в применении передачи СВЧ-сигнала по оптоволоконным линиям [1-3]. В этом случае при использовании длины волны излучения $1.55 \mu \mathrm{m}$, соответствующей минимуму потерь распространенного оптического волокна на основе окиси кремния, погонные потери мощности снижаются до $0.2 \mathrm{~dB} / \mathrm{km}$, что позволяет реализовать передачу сигналов на расстояния в десятки километров. При этом канал передачи является нечувствительным к электромагнитным помехам и обеспечивает гальваническую развязку передатчика и приемника. Для построения таких волоконнооптических систем передачи СВЧ-сигналов требуются полупроводниковые лазеры, модуляторы и фотодиоды на выбранный спектральный диапазон, при этом эффективность передачи сигнала и динамический диапазон канала передачи прямо зависят от мощности используемого источника излучения и величины фототока фотоприемника. К настоящему времени предложены различные конструкции СВЧ-фотодиодов - с двойной обедненной областью, с частично обедненным поглощающим слоем и фотодиоды с униполярной проводимостью (UTC) [4], значения выходной мощности которых в большинстве случаев не превышают единиц милливатт. Для ряда применений, однако, требуются фотодетекторы, обеспечивающие выходную мощность в десятки-сотни милливатт при полосе пропускания до 10-50 GHz. Задача изготовления мощных СВЧ-фотодиодов, имеющих такие характеристики, ставит технологические проблемы, обусловленные в значительной части необходимостью оптимизации конструкции гетероэпитаксиальной структуры (ГЭС) и трудностями отвода тепла от области малого объема, в которой в таком приборе протекает фототок. Рекордные значения выходной мощности для указанного частотного диапазона показывают модифицированные варианты UTC-фотодиодов, продемонстрировавшие при использовании алмазного теплоотвода выходную мощность до $1.86 \mathrm{~W}$ на частоте $10 \mathrm{GHz}$ [5].

Несмотря на значительное количество опубликованных результатов и вариантов исполнения СВЧ-фотодиодов, разработка технологических приемов их изготовления и конструкций продолжает оставаться актуальной. В настоящей работе описаны конструкция и технология изготовления мощных СВЧ-фотодиодов для спектрального диапазона $1.0-1.65 \mu \mathrm{m}$, выполненных в 
виде мезафотодиодов с барьером Шоттки с обратной засветкой. Первые результаты, полученные с фотодиодами с барьером Шоттки, были приведены нами в работе [6]. Изготовлены фотодиоды с диаметрами мез от 10 до $40 \mu \mathrm{m}$. Рабочая частота фотодиодов диаметром $10 \mu \mathrm{m}$ достигает $40 \mathrm{GHz}$, а максимальная выходная СВЧ-мощность на частоте $20 \mathrm{GHz}$ для фотодиодов диаметром $15 \mu \mathrm{m}$ равна $58 \mathrm{~mW}$. Исследованы характеристики амплитудно-фазового преобразования фотодиодов и показана перспективность их применения в системах передачи аналоговых СВЧ-сигналов с высокими требованиями к фазовым шумам.

\section{1. Конструкция фотодиода}

Конструкция фотодиодов является развитием предложенной ранее в работе [7]. Поперечное сечение мощного СВЧ-фотодиода с барьером Шоттки на основе ГЭС $\mathrm{In}_{0.52} \mathrm{Al}_{0.48} \mathrm{As} / \mathrm{In}_{0.53} \mathrm{Ga}_{0.47} \mathrm{As}$ схематически показано на рис. $1, a$, а его зонная диаграмма - на рис. $1, b$. Фотодиод представляет собой мезаструктуру круглого сечения с массивными металлическими контактными выводами и состоит из следующих элементов:

1. Полуизолирующая подложка InP, на тыльную сторону которой нанесено просветляющее покрытие на длину волны $1.55 \mu \mathrm{m}$.

2. Контактный слой $n^{+}-\mathrm{In}_{0.52} \mathrm{Al}_{0.48} \mathrm{As}$ толщиной $300 \mathrm{~nm}$ c концентрацией легирующей примеси $5 \cdot 10^{18} \mathrm{~cm}^{-3}$, прозрачный для ИК-излучения (ширина запрещенной зоны $1.44 \mathrm{eV})$.

3. Поглощающий излучение слой $\mathrm{In}_{0.53} \mathrm{Ga}_{0.47} \mathrm{As}$, разделенный на две области для минимизации влияния эффекта захвата носителей заряда на гетерогранице InAlAs/InGaAs: $n^{+}$-слой толщиной $50 \mathrm{~nm}$ с концентрацией легирующей примеси $5 \cdot 10^{18} \mathrm{~cm}^{-3}$ и нелегированный слой толщиной 500-1200 nm с концентрацией примеси $<10^{15} \mathrm{~cm}^{-3}$.

4. Варизонный нелегированный слой $\operatorname{In}_{x} \mathrm{Ga}_{y} \mathrm{Al}_{1-x-y} \mathrm{As}$ толщиной $30 \mathrm{~nm}$ переходного состава, изменяющегося от $\mathrm{In}_{0.53} \mathrm{Ga}_{0.47} \mathrm{As}$ на границе с поглощающим слоем до $\mathrm{In}_{0.52} \mathrm{Al}_{0.48} \mathrm{As}$, необходимый также для устранения захвата носителей заряда на гетерогранице.

5. Нелегированный барьерный слой $n-\operatorname{In}_{0.52} \mathrm{Al}_{0.48} \mathrm{As}$ толщиной $30 \mathrm{~nm}$. Используется для увеличения высоты барьера Шоттки и тем самым значительного снижения величины темнового тока фотодиода.

6. Металлический контакт Шоттки Ti/Au к нелегированному барьерному $n$ - $\mathrm{In}_{0.52} \mathrm{Al}_{0.48} \mathrm{As}$-слою. Помимо основной функции - разделения фотогенерированных носителей - выполняет также роль зеркала для излучения, прошедшего сквозь поглощающий слой, что обеспечивает увеличение доли поглощенного излучения.

7. Металлический омический контакт $\mathrm{Ge} / \mathrm{Au} / \mathrm{Ni} / \mathrm{Au}$ к контактному слою $n^{+}-\operatorname{In}_{0.52} \mathrm{Al}_{0.48} \mathrm{As}$.

8. Массивные выводы толщиной до $5 \mu \mathrm{m}$, формируемые осаждением золота на металлические контакты.

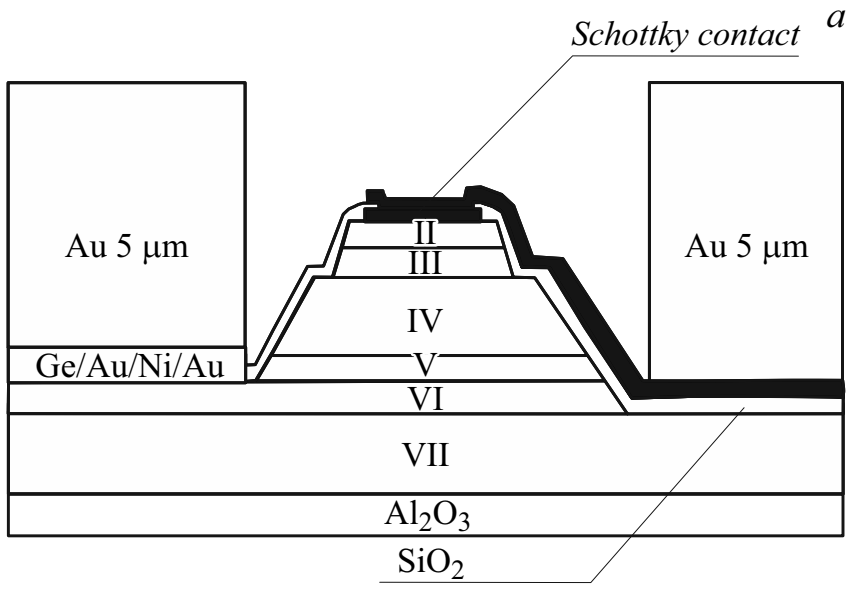

$b$

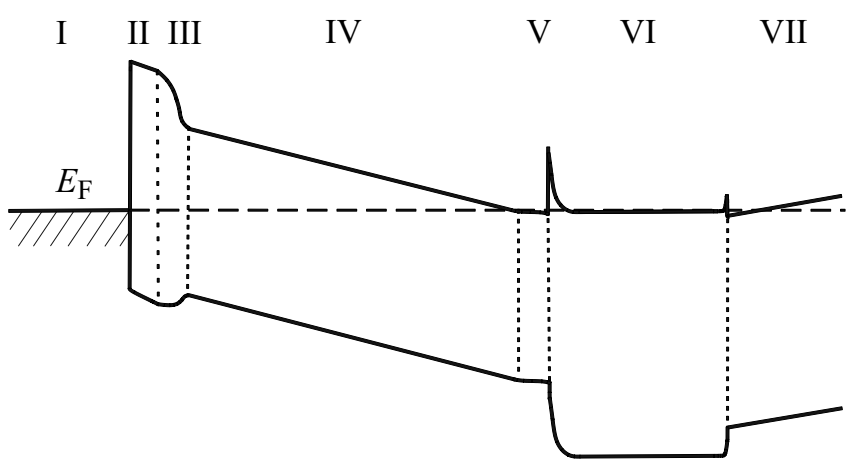

Рис. 1. $a-$ схема мезаструктуры фотодиода с барьером Шоттки (не в масштабе) и $b-$ его зонная диаграмма. Области структуры: I - металл, II - барьерный слой $\mathrm{In}_{0.52} \mathrm{Al}_{0.48} \mathrm{As}$, III - варизонный слой $\mathrm{In}_{x} \mathrm{Ga}_{y} \mathrm{Al}_{1-x-y} \mathrm{As}$, IV, $\mathrm{V}$ - поглощающий слой $\operatorname{In}_{0.53} \mathrm{Ga}_{0.47} \mathrm{As}$, VI - контактный слой $n^{+}-\mathrm{In}_{0.52} \mathrm{Al}_{0.48} \mathrm{As}$, VII - подложка InP. Вертикальные пунктирные линии отмечают границы между слоями ГЭС, $E_{\mathrm{F}}-$ уровень Ферми $(b)$.

Использование массивных контактных выводов позволяет уменьшить электрическое и тепловое сопротивление конструкции, а их индуктивность может быть использована для увеличения предельной рабочей частоты фотодиода $[7,8]$.

\section{2. Изготовление фотодиодов}

Фотодиоды изготавливались на основе многослойных полупроводниковых ГЭС InAlAs/InGaAs/InP, выращенных методом молекулярно-лучевой эпитаксии (МЛЭ). Выращивание ГЭС производилось в установке МЛЭ „Compact-21T“ производства Riber (Франция) на epi-ready подложках полуизолирующего (001) InP, легированного $\mathrm{Fe}$. Перед началом выращивания ГЭС подложки для очистки подвергались прогреву при температуре от 150 до $540^{\circ} \mathrm{C}$. При высоких температурах прогрев проводился в потоке мышьяка с давлением $2.5 \cdot 10^{-5}$ Torr. Контроль очистки подложки выполнялся 
с помощью регистрации картин дифракции быстрых электронов на отражение до формирования на поверхности подложки сверхструктуры $(4 \times 2)$, свидетельствующей об удалении остаточных окислов и достижении атомарной чистоты поверхности [9]. После очистки подложки рост слоев ГЭС проводился в порядке, описанном в разд. 1. Для защиты от окисления при контакте c атмосферой барьерный слой ГЭС защищался слоем $\mathrm{In}_{0.53} \mathrm{Ga}_{0.47} \mathrm{As}$ толщиной $30 \mathrm{~nm}$. Выращивание слоев $\mathrm{In}_{0.52} \mathrm{Al}_{0.48} \mathrm{As}$ и $\mathrm{In}_{0.53} \mathrm{Ga}_{0.47} \mathrm{As}$ ГЭС производилось при температуре подложки 520 и $480^{\circ} \mathrm{C}$ соответственно. Контроль состава слоев твердого раствора $\operatorname{In}_{x} \mathrm{Al}_{1-x} \mathrm{As}$ выполнялся с помощью методики фотолюминесценции на предварительно выращиваемых калибровочных ГЭС. Контроль состава $x$ твердого раствора $\operatorname{In}_{x} \mathrm{Ga}_{1-x}$ As поглощающего слоя проводился с помощью измерения спектра оптического пропускания ГЭС вблизи ширины запрещенной зоны поглощающего слоя. Толщина поглощающего слоя $d_{\mathrm{AL}}$ изменялась в серии ГЭС в диапазоне 500-1200 nm. Выбор толщины поглощающего слоя ГЭС $d_{\mathrm{AL}}$ определяется требуемыми эффективностью преобразования излучения и частотными параметрами фотодиода. Величина $d_{\mathrm{AL}}$ определяет долю поглощенного излучения, время пролета слоя фотогенерируемыми носителями заряда, задающее предельную рабочую частоту фотодиода, и емкость мезаструктуры, также влияющую на его частотные характеристики. При использовании тонкого поглощающего слоя $\left(d_{\mathrm{AL}}<1000 \mathrm{~nm}\right)$ применение сплошного металлического контакта Шоттки позволяет увеличить эффективность поглощения падающего излучения благодаря отражению контактом части излучения, прошедшего поглощающий слой, назад и его повторному проходу через область поглощения. Для определения коэффициента отражения излучения $R_{S}$ контактами Шоттки был измерен спектр отражения образца, представляющего собой ГЭС с нанесенным контактом Шоттки. При измерении неполяризованное излучение подавалось со стороны полированной подложки ГЭС под углом $45^{\circ}$ к нормали образца. Для снижения влияния интерференции волн, отраженных контактом и границей подложка-воздух, измерение проводилось при спектральном разрешении в три раза больше периода интерференции. В спектре, показанном на рис. 2, следует выделить две области. Для энергий фотона $h v$ более ширины запрещенной зоны поглощающего слоя $E_{g}$ интенсивность отраженного образцом света определяется отражением на границе InP подложки с воздухом, поскольку излучение, прошедшее границу раздела, поглощается в ГЭС. Как видно из рисунка, в этом случае величина коэффициента отражения образца для $h v>0.85 \mathrm{eV}$ равна $38 \%$, что соответствует расчету для случая отражения от фосфида индия (показатель преломления $n=3.3[10]$ ). В области прозрачности поглощающего слоя $h v<E_{g}$ коэффициент отражения образца увеличивается благодаря отражению излучения металлическим контактом и составляет $70 \%$. Расчет величины коэффициента отражения для $h v<E_{g}$

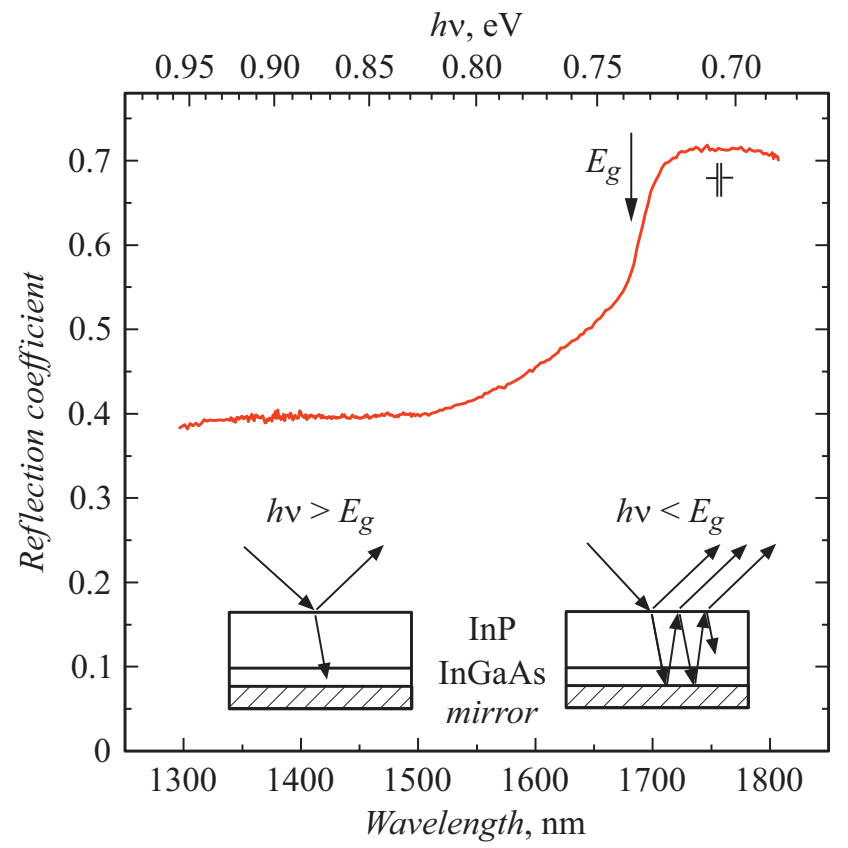

Рис. 2. Спектр отражения ГЭС с контактом Шоттки, выступающим в роли зеркала. Стрелка указывает энергию фотона, соответствующую ширине запрещенной зоны $E_{g}$ поглощающего слоя InGaAs. На вставке иллюстрируется геометрия измерения и режимы отражения для „коротковолновой“ и „длинноволновой“ частей спектра. Спектральное разрешение указано на графике.

показал, что для излучения, прошедшего поглощающий слой фотодиода, контакт Шоттки имеет коэффициент отражения $R_{S}=(65 \pm 5) \%$. Расчет проводился с учетом интерференции для системы в виде прозрачного плоскопараллельного слоя полупроводника с показателем преломления $n=3.15$, граничащего со средой с $n=1$ с одной стороны и зеркалом с другой. Полученное значение $R_{S}$ используется при расчете скорости генерации носителей при поглощении излучения и выборе толщины поглощающего слоя.

Фотодиоды на ГЭС InAlAs/InGaAs/InP изготавливались методом планарной технологии. Мезаструктуры диаметром от 10 до $40 \mu \mathrm{m}$ формировались химическим травлением. Омический контакт к контактному слою $n^{+}-\mathrm{In}_{0.52} \mathrm{Al}_{0.48} \mathrm{As}$ изготавливался напылением последовательности слоев $\mathrm{Ge}(20 \mathrm{~nm}) / \mathrm{Au}(40 \mathrm{~nm}) / \mathrm{Ni}(20 \mathrm{~nm}) /$ $\mathrm{Au}(200 \mathrm{~nm})$ с последующим вжиганием в водороде при температуре $385^{\circ} \mathrm{C}$. Барьер Шоттки на нелегированном слое $\operatorname{In}_{0.52} \mathrm{Al}_{0.48} \mathrm{As}$ изготавливался путем осаждения слоев $\mathrm{Ti}(20 \mathrm{~nm}) / \mathrm{Au}(200 \mathrm{~nm})$ после удаления химическим травлением защитного слоя $\operatorname{In}_{0.53} \mathrm{Ga}_{0.47} \mathrm{As}$ и естественного оксидного слоя InAlAs. Для межслойной изоляции, защиты и пассивации поверхности мезаструктуры использовались слои $\mathrm{SiO}_{2}$ толщиной $800 \mathrm{~nm}$, синтезируемые методом осаждения из газовой фазы низкого давления при температуре $250^{\circ} \mathrm{C}$. Внешний вид фотодиодной структуры до изготовления массивных кон- 


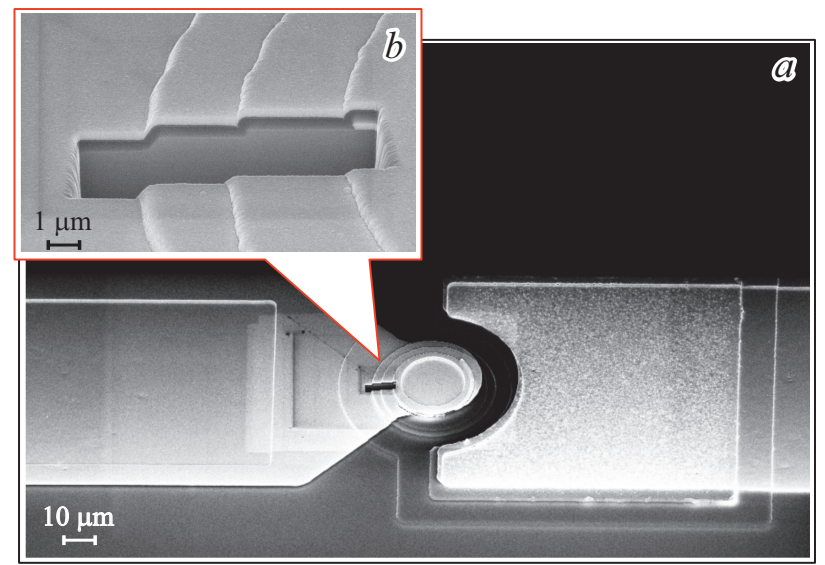

Pис. 3. $a-$ мезафотодиод до изготовления массивных контактов. Слева от центра диода методом травления фокусированным ионным пучком выполнен разрез мезы, обеспечивающий контроль качества осажденных слоев. На вставке $(b)$ область разреза показана в увеличенном виде.

тактов и поперечный разрез в области мезаструктуры, полученные с помощью сканирующего электронного микроскопа Zeiss Cross Beam 1540XB, показаны на рис. $3, a$ и $b$ соответственно. Для обеспечения электрического и теплового контакта фотодиода в дальнейшем на контактные и барьерные металлические площадки электролитическим методом осаждался слой золота толщиной до $5 \mu \mathrm{m}$. Затем на утоненную механическим шлифованием с последующей полировкой подложку наносилось просветляющее покрытие из $\mathrm{Al}_{2} \mathrm{O}_{3}$.

\section{3. Характеристики фотодиодов}

Измерение низкочастотных характеристик фотодиодов проводилось с помощью зондовой станции Cascade M150 и анализатора параметров полупроводниковых приборов Agilent 1500B, излучение полупроводникового лазера с длиной волны $1.55 \mu \mathrm{m}$ подавалось через одномодовое волокно со стороны подложки фотодиода. Для измерения СВЧ-параметров чипы фотодиодов монтировались методом перевернутого кристалла на носители с выполненными на них копланарными линиями передачи с волновым сопротивлением $50 \Omega$. Измерения выполнялись с помощью стенда на основе одночастотного полупроводникового лазера с усилителем, электрооптического модулятора Маха-Цандера с полосой частот $40 \mathrm{GHz}$, векторного анализатора Anritsu MS4645В и измерителя мощности Anritsu MA24126A.

Вольт-амперные характеристики изготовленных фотодиодов соответствовали полученным ранее для барьеров Шоттки на InAlAs $[6,11]$ и характеризовались высотой барьера $0.7 \mathrm{~V}$ и коэффициентом идеальности 1.2. Значения обратного тока при напряжении $-3 \mathrm{~V}$, усредненные по выборкам из 20 чипов каждая, для фотодиодов диаметром 10, 15 и $40 \mu \mathrm{m}$ составляли соответственно
0.04, 0.1 и $0.3 \mathrm{nA}$. Эффективность преобразования на постоянном токе для длины волны излучения $1.55 \mu \mathrm{m}$ составляла $0.65,0.72,0.87$ и $1.05 \mathrm{~A} / \mathrm{W}$ для фотодиодов с толщиной поглощающего слоя $d_{\mathrm{AL}}=500,600,900$ и $1200 \mathrm{~nm}$ соответственно, что находится в согласии с расчетом с учетом отражения излучения металлическим контактом Шоттки. Для минимизации влияния времени пролета поглощающего слоя при измерении СВЧ-характеристик использовались фотодиоды с наименьшей толщиной поглощающего слоя $d_{\mathrm{AL}}=500 \mathrm{~nm}$. На рис. 4 показаны амплитудно-частотные характеристики (АЧХ) фотодиодов диаметром 10 и $15 \mu \mathrm{m}$, имеющих наименьшие значения емкости структуры. Низкочастотный срез

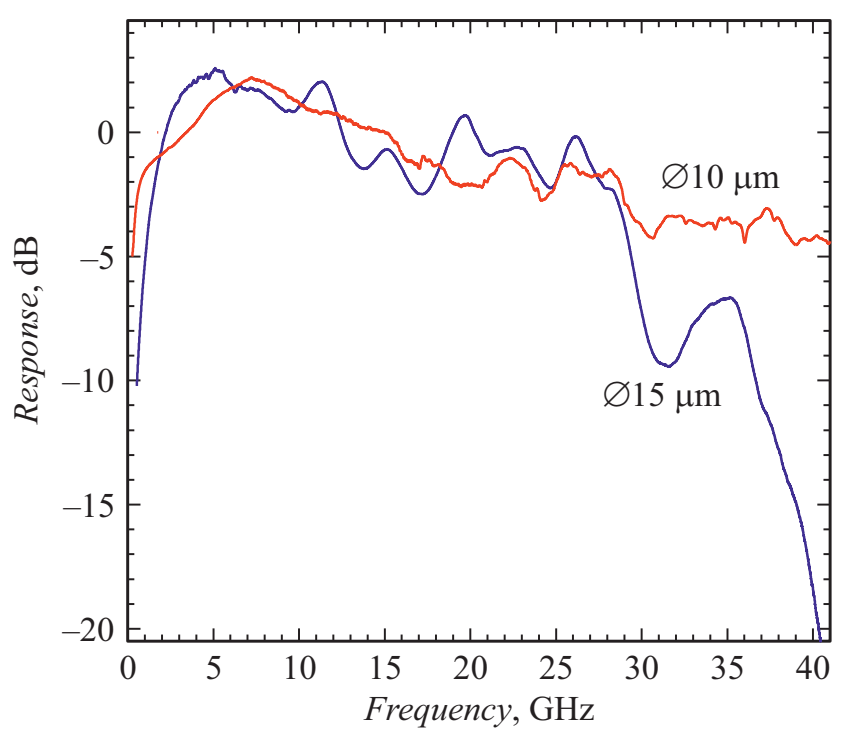

Рис. 4. Амплитудно-частотные характеристики фотодиодов с диаметром мезы 10 и $15 \mu \mathrm{m}$.

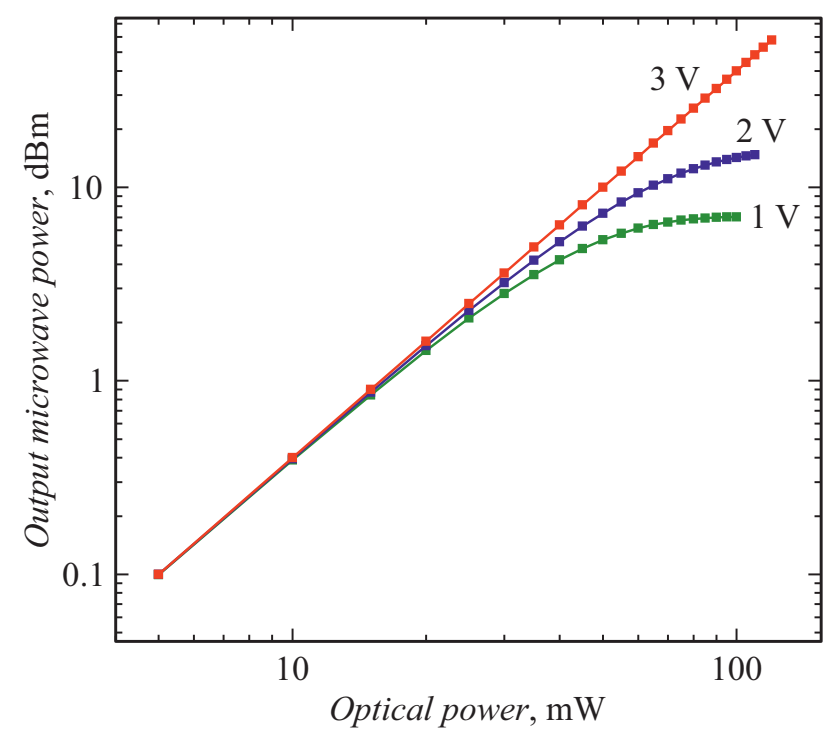

Рис. 5. Зависимость выходной СВЧ-мощности фотодиода диаметром $15 \mu \mathrm{m}$ от мощности входного оптического излучения при частоте модуляции $20 \mathrm{GHz}$ для напряжения смещения в диапазоне $1-3 \mathrm{~V}$. 

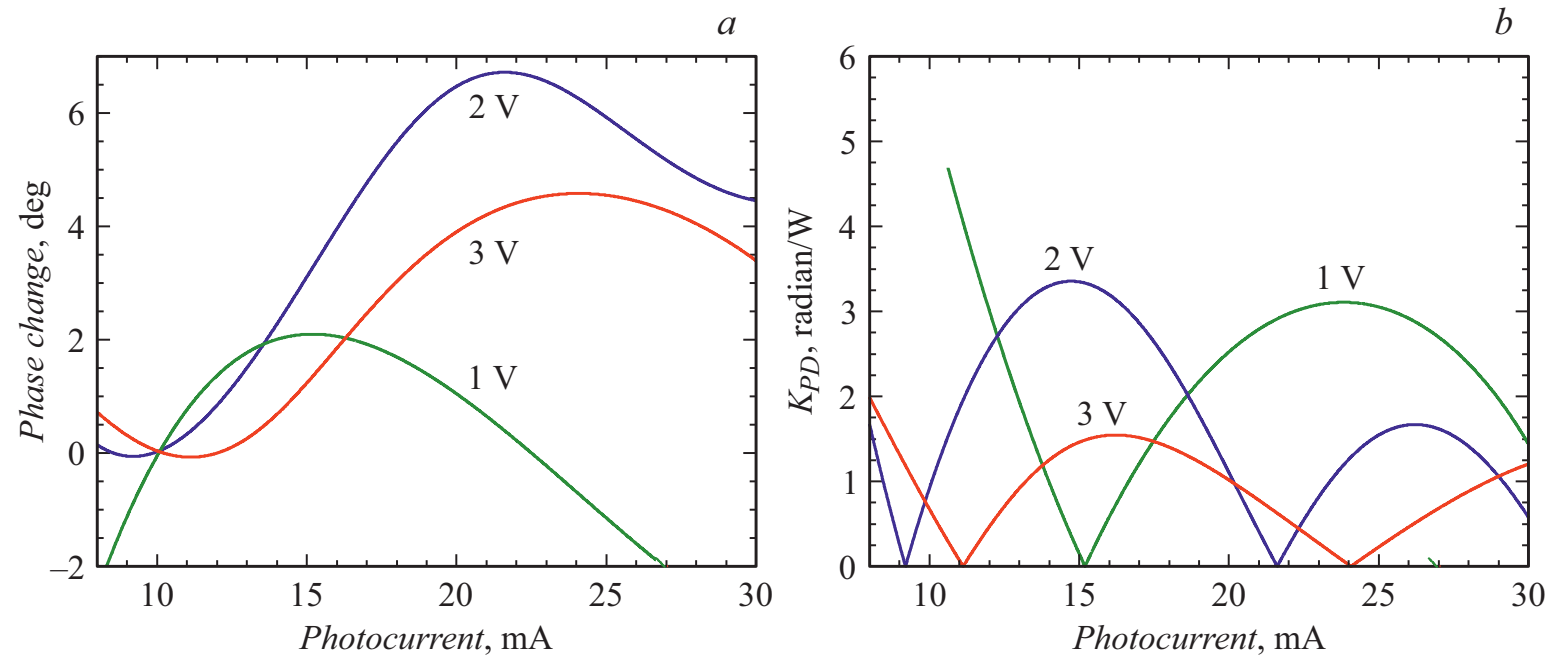

Рис. 6. Зависимости (a) фазы выходного СВЧ-сигнала фотодиода и $(b)$ коэффициента АМ-РМ конверсии от мощности входного оптического сигнала для напряжения смещения в диапазоне $1-3 \mathrm{~V}$. Частота модуляции $20 \mathrm{GHz}$. Мощность входного сигнала характеризуется величиной среднего фототока фотодиода.

АЧХ обусловлен использованием схемы питания фотодиода с фильтром высоких частот, неоднородности в виде „модуляций“ связаны с неполным согласованием импедансов в СВЧ-тракте. Как видно из рисунка, частотный диапазон фотодиода диаметром $15 \mu \mathrm{m}$ ограничен $28-30 \mathrm{GHz}$, в то время как фотодиод диаметром $10 \mu \mathrm{m}$ обладает частотным диапазоном до $40 \mathrm{GHz}$. Максимальная выходная мощность СВЧ-сигнала была получена для диодов диаметром $15 \mu \mathrm{m}$. На рис. 5 показаны зависимости выходной СВЧ-мощности такого фотодиода от входной мощности модулированного светового потока при частоте модуляции $20 \mathrm{GHz}$. Наибольшая выходная мощность СВЧ-фотодиода, соответствующая границе теплового разрушения прибора, достигла $58 \mathrm{~mW}$.

Важной характеристикой фотодиодов, используемых в системах передачи аналоговых СВЧ-сигналов, является величина изменения фазы выходного сигнала при изменении мощности входного модулированного излучения. Изменение фазы с интенсивностью излучения приводит к амплитудно-фазовому преобразованию (АМ-РМ конверсии) и появлению дополнительных фазовых шумов выходного сигнала за счет конверсии шума интенсивности источника излучения $[12,13]$, что существенно для устройств, чувствительных к фазе сигнала, включая осцилляторы и многоканальные системы со связанными фазами сигналов. Для исследования величины коэффициента амплитудно-фазового преобразования (коэффициента АМ-PМ конверсии) $K_{P D}=\Delta \varphi_{P D} / \Delta P_{\text {opt }}(\mathrm{rad} / \mathrm{W})$ фотодиодов, где $\Delta \varphi_{P D}-$ изменение фазы выходного сигнала и $\Delta P_{\text {opt }}$ - изменение мощности входного излучения, были измерены зависимости фазы выходного сигнала от мощности входного оптического пучка. Измерение проводилось при частоте модуляции $20 \mathrm{GHz}$, для измерения мощности падающего пучка использовалась средняя величина фототока, измеряемого в цепи питания фотодиода. Для повышения однородности освещения рабочей площадки фотодиода падающее излучение дефокусировалось, при этом эффективность преобразования фотодиода равнялась $0.2 \mathrm{~A} / \mathrm{W}$. На рис. $6, a$ показаны зависимости фазы выходного сигнала от мощности входного для фотодиода диаметром $15 \mu \mathrm{m}$, полученные для различных напряжений обратного смещения. Как видно из рисунка, изменение сдвига фазы с мощностью немонотонно. Рассчитанная по этим данным величина коэффициента амплитудно-фазового преобразования в зависимости от мощности показана на рис. $6, b$. Величина $K_{P D}$ для напряжения смещения $-3 \mathrm{~V}$, обеспечивающего получение наибольшей выходной мощности СВЧ-сигнала фотодиода, не превышает $1.5 \mathrm{rad} / \mathrm{W}$ и близка к нулю при значении среднего фототока фотодиода $24 \mathrm{~mA}$. Для сравнения, опубликованные данные коэффициента KPD фотодиодов серии XHPLD компании Discovery Semiconductor, Inc. ограничены величиной $5 \mathrm{rad} / \mathrm{W}$ [14]. Значения коэффициента амплитудно-фазового преобразования оптимизированных UTC-фотодиодов, приводимые с нормировкой на относительное изменение мощности, составили $6.5-9.5^{\circ}$ на частоте $15 \mathrm{GHz}$ в аналогичном диапазоне токов [15], что соответствует величинам $K_{P D}=3.6-4.6 \mathrm{rad} / \mathrm{W}(4.8-6.2 \mathrm{rad} / \mathrm{W}$ при пересчете для частоты $20 \mathrm{GHz})$. Значительно меньшая величина коэффициента АМ-РМ конверсии в фотодиодах Шоттки указывает на перспективность такой конструкции для применений в скоростных линиях передачи аналоговых данных с высокими требованиями к величине фазового шума.

\section{Заключение}

Рассмотрены конструкция и технология изготовления мощных высокочастотных мезафотодиодов с ба- 
рьером Шоттки, полученных на основе гетероструктур InGaAs/InAlAs/InP, синтезируемых методом молекулярно-лучевой эпитаксии. Показано, что чувствительность фотодиодов на постоянном токе составляет до $1.05 \mathrm{~A} / \mathrm{W}$, темновой ток равен 0.04-0.3 nА для диаметра фотодиодов $10-40 \mu \mathrm{m}$ соответственно. Фотодиоды демонстрируют полосу частот в 28 и $40 \mathrm{GHz}$ для диаметра мезы 15 и $10 \mu \mathrm{m}$ соответственно, и выходную мощность на частоте $20 \mathrm{GHz}$ до $58 \mathrm{~mW}$. Обнаружено, что коэффициент амплитудно-фазового преобразования (АМ-РМ конверсии) фотодиодов с барьером Шоттки более чем в три раза ниже, чем ранее опубликованные литературные данные, что показывает перспективность этой конструкции фотодиодов для работы в системах с высокими требованиями к величине фазового шума передаваемого СВЧ-сигнала.

\section{Благодарности}

Контроль внешнего вида структур и измерение низкочастотных характеристик фотодиодов выполнялись в Центре коллективного пользования „Наноструктуры“ ИФП СО РАН.

\section{Финансирование работы}

Изготовление гетероструктур, использованных в работе, было поддержано Российским научным фондом в рамках проекта 19-72-30023. Изготовление и тестирование макетов было поддержано Российским фондом фундаментальных исследований в рамках проекта № 20-52-26013.

\section{Конфликт интересов}

Авторы заявляют, что у них нет конфликта интересов.

\section{Список литературы}

[1] A.J. Seeds, K.J. Williams. J. Lightwave Technol., 24 (12), 4628 (2006). DOI: 10.1109/JLT.2006.885787

[2] T. Berceli, P.R. Herczfeld. IEEE Trans. Microw. Theor. Tech., 58 (11), 2992 (2010). DOI: 10.1109/TMTT.2010.2076932

[3] W.S.C. Chang, editor. RF Photonic Technology in Optical Fiber Links (Cambridge University Press, NY., 2002)

[4] И.Б. Чистохин, К.С. Журавлев. Успехи прикладной физики, 3 (1), 92 (2015). [I.B. Chistokhin, K.S. Zhuravlev. Uspekhi Prikladnoj Fiziki, 3 (1), 92 (2015) (in Russian).]

[5] X. Xie, Q. Zhou, K. Lim, Y. Shen, Q. Lim, Z. Yang, A. Beling, J.C. Campbell. Optica, 1 (6), 429 (2013).

DOI: $10.1364 /$ OPTICA.1.000429

[6] А.Л. Чиж, К.Б. Микитчук, К.С. Журавлев, Д.В. Дмитриев, А.И. Торопов, Н.А. Валишева, М.С. Аксенов, А.М. Гилинский, И.Б. Чистохин. Письма в ЖТФ, 45 (14), 52 (2019). DOI: 10.21883/PJTF.2019.14.48026.17764 [A.L. Chizh, K.B. Mikitchuk, K.S. Zhuravlev, D.V. Dmitriev, A.I. Toropov, N.A. Valisheva, M.S. Aksenov, A.M. Gilinsky, I.B. Chistokhin. Tech. Phys. Lett., 45(7), 739 (2019). DOI: $10.1134 / \mathrm{S} 1063785019070204]$
[7] A. Chizh, S. Malyshev, K. Mikitchuk. 2015 International Topical Meeting on Microwave Photonics (MWP) - Paphos, Cyprus, 24-29 October, 2015, p. 1. DOI: $10.1109 /$ mwp.2015.7356654

[8] R. Lewen, U. Westergren, R. Schatz, E. Berglind. J. Lightwave Technol., 19 (12), 1956 (2001).

[9] S. Katsura, Y. Sugiyama, O. Oda, M. Tacano. Appl. Phys. Lett., 62 (16), 1910 (1993). DOI: 10.1063/1.109540

[10] S. Adachi. J. Appl. Phys., 66 (12), 6030 (1989). DOI: $10.1063 / 1.343580$

[11] M.S. Aksenov, N.A. Valisheva, I.B. Chistokhin, D.V. Dmitriev, A.S. Kozhukhov, K.S. Zhuravlev. Appl. Phys. Lett., 114 (22), 221602 (2019). DOI: 10.1063/1.5091598

[12] D. Eliyahu, D. Seidel, L. Maleki. IEEE Trans. on Microw. Theor. Tech., 56 (2), 449 (2008). DOI: 10.1109/TMTT.2007.914640

[13] Y. Hu, C. Menyuk, X. Xie, M. Hutchinson, V. Urick, J. Campbell, K. Williams. IEEE Photonics J., 9 (2), 5501111 (2017). DOI: 10.1109/JPHOT.2017.2682251

[14] Электронный ресурс. Режим доступа: https://www.discoverysemi.com/Product_Pages/DSC-xHLPD.php

[15] J. Zang, X. Xie, Q. Yu, Z. Yang, A. Beling, J.C. Campbell. J. Lightwave Technol., 36 (22), 5218 (2018). DOI: $10.1109 / J L T .2018 .2871882$ 